\title{
A DIDÁTICA E SUAS CONTRIBUIÇÕES PARA A PRÁTICA DOCENTE
}

\section{REVISÃO BIBLIOGRÁFICA}

CARDOSO, Ana Carolina Grangeia ${ }^{1}$

CARDOSO, Ana Carolina Grangeia. A didática e suas contribuições para a prática docente. Revista Científica Multidisciplinar Núcleo do Conhecimento. Ano 06, Ed. 08, Vol. 05, pp. 05-17. Agosto de 2021. ISSN: 2448-0959, Link de acesso: https://www.nucleodoconhecimento.com.br/educacao/contribuicoes, DOI: 10.32749/nucleodoconhecimento.com.br/educacao/contribuicoes

\section{RESUMO}

Este artigo tem como objetivo compreender as principais contribuições da didática para a prática docente, a partir da seguinte questão norteadora: quais elementos da didática podem fomentar o aperfeiçoamento do desempenho dos professores? Dessa forma, realizou-se uma pesquisa bibliográfica sobre o tema focalizando os aspectos teóricos do seu surgimento, definição de objetivos educacionais, o planejamento educacional, a seleção e organização de conteúdo, os métodos de ensino e a avaliação da aprendizagem. Assim, conclui-se que todos os educadores e profissionais da área precisam conhecer os elementos relacionados à didática que podem auxiliar no aprimoramento do trabalho docente tendo em vista a melhoria da qualidade da educação.

Palavras-Chave: didática, educadores, trabalho docente.

\footnotetext{
${ }^{1}$ Pedagoga e Mestre em Educação pela Universidade Federal Fluminense. Especialista em Gestão Escolar (administração, supervisão e orientação) e Gestão Pública.
}

RC: 94591

Disponível em: https://www.nucleodoconhecimento.com.br/educacao/contribuicoes 


\section{INTRODUÇÃO}

Apesar de já existirem indícios de formas elementares de instrução e aprendizagem ao longo da história da educação, o termo "didática" surge quando os adultos começaram a intervir na atividade de aprendizagem, definindo-a como atividade planejada e intencional. Nesse contexto, iniciou-se um processo de estabelecimento de princípios e regras de ensino, buscando a melhoria do desempenho docente e o desenvolvimento da capacidade de identificar como os alunos aprendem (LIBÂNEO, 2013). Diante disso, torna-se necessário conhecer e reconhecer as diversas técnicas e os métodos educacionais existentes que promovem a melhoria da qualidade da educação.

A Didática pode ser situada no conjunto dos conhecimentos pedagógicos com papel significativo na formação profissional para o exercício do magistério (LIBÂNEO, 2013). Por meio dela, os docentes adquirem os ensinamentos necessários para o desenvolvimento de sua prática. O processo de ensino, objeto de estudo da Didática, não pode ser considerado como atividade restrita à sala de aula. Diante disso, os docentes necessitam conhecer os métodos e formas organizativas do ensino, bem como as diretrizes que regulam e orientam o seu processo (LIBÂNEO, 2013).

É fundamental que os educadores se apropriem da didática como elemento mediador do seu trabalho. Portanto, o objetivo do presente artigo é compreender as principais contribuições da didática para a prática docente, a partir da seguinte questão norteadora: quais elementos da didática podem fomentar o aperfeiçoamento do desempenho dos professores? Para tal, este trabalho focaliza os aspectos teóricos do seu surgimento e as questões que envolvem a escolha dos objetivos educacionais, o planejamento educacional, a seleção e organização de conteúdo, os métodos de ensino e a avaliação da aprendizagem, a partir de uma revisão bibliográfica sobre o tema.

Ao entender a Didática como disciplina da formação docente, busca-se, com esse trabalho, que os profissionais da educação encontrem aqui a fundamentação teórica 
necessária para construir suas práticas de forma a tornar o processo de ensino e aprendizagem o mais significativo possível aos discentes.

\section{DIDÁTICA: UM BREVE HISTÓRICO E SEU SIGNIFICADO}

A preocupação com as formas de ensinar e aprender não é recente. Os registros históricos mostram que o primeiro educador, Platão, surgiu na Grécia Antiga. Já a partir do século VI, destaca-se o papel da Igreja na educação, a qual passou a dedicar seu tempo a criação de escolas para a garantia da formação cristã das pessoas nas grandes cidades europeias. Durante o séc. XI e XII, com a necessidade de atender aos interesses comerciais, o controle da educação formal foge das mãos da Igreja (MALHEIROS, 2019).

A constituição da escola por séries, como conhecemos hoje, foi introduzida com os jesuítas, na Idade Moderna. O processo de separação das turmas começou no séc. XVII, momento em que se passou a dividir em ensino primário (classes populares) e ensino secundário (burguesia) (MALHEIROS, 2019).

O séc. XII foi o marco da Didática com a publicação da Didacta Magna de Comênio. Essa publicação teve o objetivo de estruturar as formas de ensinar, defendendo uma ideia de universalização do ensino. Após Comênio, alguns teóricos apresentaram conceitos importantes para o desenvolvimento do processo de ensino, tais como Rousseau, Pestalozzi e Herbart. Segundo Libâneo, Comênio foi o "primeiro educador a formular uma ideia da difusão dos conhecimentos a todos e criar princípios e regras do ensino" (LIBÂNEO, 2013, p.60).

o termo Didática aparece quando os adultos começam a intervir na atividade de aprendizagem das crianças e jovens através da direção deliberada e planejada do ensino, ao contrário das formas de intervenção mais ou menos espontâneas de antes. Estabelecendo-se uma intenção propriamente pedagógica na atividade de ensino, a escola se torna uma instituição, o processo de ensino passa a ser sistematizado conforme níveis, tendo em vista a adequação às possibilidades das crianças, às idades e ritmos de assimilação dos estudos (LIBÂNEO, 2013, p.59). 
Rousseau (1712-1228), de acordo com Malheiros (2019), pregava que a educação deveria preparar a criança para a vida adulta tendo como estrutura as necessidades reais. Para ele, o processo de aprendizagem é um processo natural, ligado ao desenvolvimento biológico. No mesmo sentido, Libâneo (2013) diz que o ensino deve ser voltado aos interesses das crianças que são boas por natureza.

Anos mais tarde, Pestalozzi (1746-1827) desenvolveu um método de ensino, no qual defendia a observação e a análise como formas de captar a realidade, levando a criança a construir seus próprios significados sobre os diversos fenômenos, que deveriam ser expressos e avaliados por meio da linguagem (MALHEIROS, 2019). Pestalozzi colocou em prática as ideias de Rousseau. Seu método de ensino era baseado na intuição, cultivo do sentimento, mente e caráter (LIBÂNEO, 2013). Após Pestalozzi, outro nome de destaque nos estudos da Didática foi Herbert. Ele foi influenciado por Rousseau, Pestalozzi e Comênio (MALHEIROS, 2019).

Herbert (1766-1841) tinha o objetivo de formular um método único de ensino que atendesse a todas as pessoas, priorizando a organização da prática docente, como por exemplo: "a necessidade de estruturação e ordenação do processo de ensino, a exigência de compreensão dos assuntos estudados e não simplesmente memorização e o significado educativo da disciplina na formação do caráter" (LIBÂNEO, 2013, p 63). Nesse momento, buscou-se direcionar as ações instrucionais pela forma como as pessoas aprendem (LIBÂNEO, 2013).

A partir do séc. XIX e início do séc. XX, Idade Contemporânea, surge a demanda por uma cultura uniformizada. A escola contemporânea é construída a partir das seguintes diretrizes: espaços escolares claramente definidos, horários rígidos, seleção de conteúdos apropriados para cada série, desmerecimento de práticas de ensino não institucionalizadas, obrigatoriedade de frequência e avaliação e certificação da aprendizagem (MALHEIROS, 2019). Ainda no século XIX, a Didática passou a buscar fundamentos nas ciências, especialmente na Biologia e Psicologia. Surge, assim, a Pedagogia da "Escola Nova", na qual o aluno se auto educa e é o sujeito da aprendizagem, enquanto o professor é o incentivador, orientador e organizador das situações de aprendizagem (GIL, 2018). 
A Escola Nova pretendia ser um movimento de renovação pedagógica de cunho fundamentalmente técnico, que buscavam aplicar na prática educativa os conhecimentos derivados das ciências do comportamento. Com efeito, a partir da segunda década do século XX, a Didática passou a seguir os postulados da Escola Nova. Com essa perspectiva afirmava a necessidade de partir dos interesses espontâneos e naturais da criança, passou a valorizar os princípios de atividade, liberdade e individualização. Abandonou-se a visão que a criança é um adulto em miniatura... (GIL, 2018, p. 3)

No Brasil, as ideias da Escola Nova foram muito prestigiadas após a Revolução de 1930 através de Fernando de Azevedo, Anísio Teixeira e Lourenço Filho. O período de 1950 até 1970 é marcado pelo uso de métodos e técnicas de ensino com o objetivo de garantir a eficiência da aprendizagem dos alunos e a defesa da neutralidade científica (tecnicismo). Diante disso, a Didática, como disciplina, passou a enfatizar a elaboração de planos de ensino, formulação de objetivos instrucionais, seleção de conteúdos, técnicas de exposição etc. (GIL, 2018).

Com o passar dos anos e com o aprimoramento dos estudos na área da educação, o campo da didática começa a ser delineado de maneira sólida. O senso comum acredita que a educação só acontece na escola. Porém, na escola acontece a educação formal, marcada pelas características de intencionalidade, sistematização, organização e relação social, forma sistemática da educação. Por outro lado, a educação informal é aquela que não ocorre em um espaço e tempo organizados, forma assistemática (MALHEIROS, 2019). Nessa perspectiva, Libâneo (2013) situa a educação formal dentro das instituições (escola) que promovem a educação de forma intencional e, por conseguinte, orientam suas atividades de modo a torná-las mais eficientes, por meio do planejamento, da definição de métodos, da seleção de conteúdos e da definição de processos de avaliação.

Nesse cenário, a Pedagogia e a Didática estão estritamente ligadas. A primeira é a arte e a ciência da educação. A segunda é a ciência e a arte do ensino. Didática é, portanto, o estudo de todo o processo de ensino e seus resultados (MASETTO, 1997) que se manifesta "quando os adultos começam a intervir na atividade de aprendizagem das crianças e jovens através da direção deliberada e planejada do ensino, ao contrário das formas de intervenção mais ou menos espontâneas de antes" (LIBÂNEO, 1994, p.58). 
A Didática é um elemento fundamental na forma sistemática da educação, pois possibilita que o professor execute todos os passos para realização de uma aula: processo de ensino (etapas da aula); métodos de ensino; procedimentos de aprendizagem; materiais didáticos; e gestão da situação de ensino (LIBÂNEO, 1994). Portanto, a compreensão da história da educação e da evolução da Didática revela a sua importância para os educadores e para a melhoria do processo de ensino.

\section{PLANEJAMENTO EDUCACIONAL: PERSPECTIVAS E APLICAÇÕES}

O planejamento é um "processo de racionalização, organização e coordenação da ação docente, articulando a atividade escolar e a problemática do contexto social" (LIBÂNEO, 2013, p. 246) e, por isso, é um campo de estudos importante para as instituições de ensino e para os professores. De acordo com Malheiros (2019), o planejamento educacional pode ser compreendido como a organização dos passos que serão dados para se atingir determinado objetivo, sendo divido em plano educacional e plano de ensino.

Ainda de acordo com Malheiros (2019), dentro do planejamento educacional encontramos os seguintes planos: educacional, escolar, curricular e ensino. Para ele, o plano educacional tem maior abrangência, pois trata de questões políticas e filosóficas do ato de ensinar. Nesse sentido, é um processo sistêmico que acontece em nível nacional, estadual e local. Tal plano precisa se converter em um plano em nível local. Logo, todas as escolas devem construir um plano escolar, ou seja, um planejamento que é feito com maior abrangência para a realidade de uma dada instituição (MALHEIROS, 2019).

Segundo Haydt (2006) existe um ciclo para construção de um plano escolar: sondagem e diagnóstico da realidade; definição de objetivos e das prioridades da escola; organização da rotina da escola; construção do plano de curso; definição do sistema disciplinar; atribuição de funções aos membros da equipe pedagógica. 
O planejamento curricular está dentro do planejamento educacional. É a organização dos conteúdos que serão trabalhados ao longo de determinado período. A organização curricular deve expressar coerência entre conteúdos e respeito ao potencial dos alunos. Já o plano de ensino apresenta de forma detalhada as atividades que o professor executará e propor a turma de modo a atingir os objetivos. Para isso, o professor deve ter clareza de quatro questões: objetivos, conteúdos, métodos e espaço (MALHEIROS, 2019).

A elaboração do plano de ensino, segundo Malheiros (2019), proporciona inúmeras vantagens ao professor, tais como: facilidade no cumprimento das atividades propostas; simplicidade de saber o que precisa ser avaliado; organização das ideias; explicitação das etapas aos interessados. Ele é composto por objetivos, conteúdos, procedimentos e recursos e deve possuir as características de coerência, continuidade, objetividade e precisão. Para elaborar um plano de ensino é necessário cumprir as seguintes etapas: diagnóstico; construção do plano; execução do plano; e avaliação do plano.

O planejamento de ensino é dividido em outros planejamentos mais detalhados: curso, unidade e aula. O planejamento de curso é a previsão de todos os conhecimentos que um determinado grupo de alunos será levado a construir em um período de tempo específico (semestre ou ano letivo). Deve conter: objetivos do curso; conteúdo; procedimentos de ensino; recursos; tempo e avaliação (MALHEIROS, 2019).

O planejamento da unidade é a previsão sobre como todas as aulas que tratam de um mesmo assunto acontecerão (MALHEIROS, 2019). Pilleti (1985) diz que o planejamento de uma unidade didática deve prever três etapas: apresentação, desenvolvimento e integração.

Por fim, o planejamento de aula é o detalhamento de cada uma das aulas e possui as seguintes funções: definição do objetivo da aula; detalhamento do conteúdo; descrição do procedimento; tempo; avaliação da aula (MALHEIROS, 2019). 
Além de Malheiros (2019), outros autores também trazem contribuições em suas obras a respeito do planejamento educacional. Para Gil (2018), existem quatro níveis de planejamento: educacional, institucional, curricular e do ensino. O planejamento educacional, na visão do teórico, ocorre em nível mais amplo, pois possui bases filosóficas e defini os fins últimos da educação e os meios para alcançá-la. Além disso, pode ser desenvolvido em âmbito Federal, Estadual e Municipal.

O planejamento institucional é realizado em conjunto por todos os profissionais de uma escola com o propósito de atender às diretrizes da educação nacional, bem como as necessidades locais e específicas de sua clientela. Através dele, é possível identificar a filosofia de trabalho, missão, diretrizes pedagógicas, entre outros aspectos da escola. Dele, nasce o Projeto Político Pedagógico (GIL, 2018).

Assim como Malheiros (2019), Gil (2018), defini o planejamento curricular como a organização do conjunto de ações que precisam ser desenvolvidas no âmbito de cada curso, com vista a favorecer ao máximo o processo de ensino-aprendizagem. O próximo nível de planejamento, de acordo com Gil (2018), é o de ensino. Tal planejamento, de responsabilidade do professor, "é alicerçado no planejamento curricular e visa ao direcionamento sistemático das atividades a serem desenvolvidas dentro e fora de sala de aula..." (GIL, 2018, p. 84). O plano de disciplina, plano de unidade e plano de aula são desdobramentos do plano de ensino, podendo ser definidos das seguintes formas:

O plano de disciplina constituiu uma previsão das atividades a serem desenvolvidas ao longo do ano ou do semestre letivo... De modo geral, o plano de disciplina esclarece acerca de sua duração, objetivos gerais, conteúdo programático, estratégias de ensino, recursos, didáticos e procedimentos de avaliação (GIL, 2018, p. 86)

O plano de unidade é um documento mais pormenorizado que o plano de disciplina. Os objetivos são bem mais operacionais que os do plano de disciplina, pois designam clara e precisamente os comportamentos esperados dos alunos (GIL, 2018, p .90)

O que distingue o plano de aula do plano de unidade é que este é bem mais restrito. De modo geral, limita-se à previsão do desenvolvimento a ser dado 
ao conteúdo da matéria e às atividades de ensino-aprendizagem propostas de acordo com os objetivos no âmbito de cada aula (GIL, 2018, p. 91)

Observa-se, portanto, que o planejamento escolar se desdobra em níveis de abrangência, tendo como foco desde a instituição de ensino até tudo que ocorre em uma aula. Ainda sobre o planejamento, Libâneo (2013) o divide em: plano da escola, plano de ensino e plano de aula. Segundo o autor, para que os planos sejam efetivamente instrumentos de ação, devem ser como um guia de orientação e apresentar ordem sequencial, objetividade, coerência e flexibilidade.

O plano da escola é constituído por orientações gerais da escola (objetivos gerais, orientação didática, clientela, concepção pedagógica do corpo docente etc.). O plano de ensino é a previsão dos objetivos e tarefas do trabalho docente para um ano ou semestre. Por fim, o plano de aula é o detalhamento do plano de ensino, ou seja, o desenvolvimento do conteúdo para uma aula (LIBÂNEO, 2013)

Por meio dos argumentos expostos ao longo do texto é possível compreender que o trabalho do docente, assim como o trabalho de toda a escola, deve ser cuidadosamente planejado, em diversos níveis, a fim de que os objetivos de ensino sejam alcançados.

\section{FORMULAÇÃO DE OBJETIVOS EDUCACIONAIS}

A prática educacional é direcionada para o alcance de objetivos, por meio de uma ação intencional e planejada (LIBÂNEO, 2013). Nesse sentido, nota-se que a formulação dos objetivos de ensino é uma etapa fundamental do trabalho docente, pois antecipam resultados e processos esperados do conjunto do trabalho do professor e dos alunos. Além disso, servem para orientar o professor quanto à seleção do conteúdo, a escolha de estratégias de ensino e a elaboração de instrumentos para avaliação de desempenho do estudante (GIL, 2018).

O movimento de estudo e formulação dos objetivos educacionais teve início nos Estados Unidos (EUA) e reflete a abordagem comportamentalista da educação. Os pioneiros desse movimento são Johann F. Herbert (1776-1841) e Herbert Spencer 
(1820-1903). Além de Herbert e Spencer, outros autores, como Franklin Bobbit , Ralph Tyler, Benjamin Bloom e Robert Mager ganharam destaque no campo dos objetivos educacionais (GIL, 2018).

Bobbit introduziu os princípios do taylorismo na organização do processo educacional, de acordo com as teorias mecanicistas e com a psicologia comportamentalista. Sendo assim, definiu alguns princípios básicos para o desenvolvimento do currículo que estão relacionados com a formulação de objetivos educacionais: eliminar objetivos que não sejam práticos e não possam ser alcançados; enfatizar objetivos que constituem necessidades para a vida adulta; evitar objetivos que se opunham à comunidade; envolver a comunidade no estabelecimento de objetivos; diferenciar os objetivos e sequenciar os objetivos (GIL, 2018).

Já Tyler foi responsável pela concepção de objetivos como alicerces do desenvolvimento do currículo escolar e do ensino (GIL, 2018). Ele desenvolveu algumas questões, as quais professores devem considerar no desenvolvimento do planejamento do ensino: que objetivos educacionais deve a escola procurar atingir? Que experiências educacionais podem ser úteis para alcançar esses objetivos? Como organizar eficientemente essas experiências educacionais? Como podemos ter certeza de que esses objetivos estão sendo alcançados? (GIL, 2018).

Benjamin Bloom é um dos autores mais citados nos trabalhos referentes à formulação de objetivos educacionais devido as suas contribuições ao estudo do tema com sua teoria da Taxonomia dos Objetivos Educacionais (GIL, 2018).

Para o autor, a classificação dos objetivos educacionais constitui a base para o planejamento e avaliação do currículo. Os objetivos são classificados em grau de complexidade dentro da área cognitiva, afetiva e psicomotora (GIL, 2018). Os domínios podem ser definidos da seguinte forma:

O domínio cognitivo: refere-se aos objetivos relacionados a conhecimentos, informações ou capacidades intelectuais. É o domínio a que se dá maior atenção nos cursos universitários. O domínio afetivo abrange os objetivos 
relacionados aos sentimentos, emoções, gostou ou atitudes. O domínio psicomotor, por fim, envolve os objetivos enfatizam o trabalho de natureza neuromuscular. Imitação, Manipulação, Precisão, articulação e naturalização (GIL, 2018, p. 101).

Da mesma maneira que Bloom, Robert Mager contribuiu para a formulação de objetivos específicos e mensuráveis. Os objetivos, segundo o autor, são conhecidos como comportamentais, de desempenho ou operacionais e descrevem o comportamento de uma pessoa como resultado pretendido de uma instrução (GIL, 2018).

Além desses autores, Libâneo (2013) também desenvolve algumas contribuições para esse tema, na medida em que estabelece a necessidade de distinção entre objetivos gerais e objetivos específicos. Para o autor, em um planejamento escolar, a elaboração dos objetivos gerais está relacionada ao sistema escolar, a escola e o professor que refletem o propósito mais amplo acerca do papel da escola e do ensino. Em complementação a eles, os objetivos específicos refletem os resultados esperados dos alunos.

De acordo com o exposto, é notária a contribuição que esses autores trouxeram para a prática docente em termos de formulação de objetivos educacionais. Portanto, cabe a cada um dos educadores absorverem o que há de melhor em cada teoria e compreender como os conceitos, métodos e técnicas podem proporcionar uma prática reflexiva.

\section{SELEÇÃO E ORGANIZAÇÃO DE CONTEÚDOS}

A seleção e a organização dos conteúdos devem ser analisadas como a ação recíproca entre a matéria, o ensino e o aluno, ou seja, o conteúdo a ser transmitido proporciona determinados procedimentos de ensino, que por sua vez, possibilitam formas de organização do estudo ativo dos alunos (LIBÂNEO, 2013). Os conteúdos de ensino podem ser definidos da seguinte maneira:

“... são o conjunto de conhecimentos, habilidades e hábitos, modos valorativos e atitudinais de atuação social, organizados pedagógica e didaticamente, tendo em vista a assimilação ativa e aplicação pelos alunos na

RC: 94591

Disponível em: https://www.nucleodoconhecimento.com.br/educacao/contribuicoes 
sua prática de vida. Englobam, portanto, conceitos, fatos, ideias, processos, princípios, habilidades..." (LIBÂNEO,2013, p.142)

Desse modo, verifica-se que os conteúdos são organizados em matérias de ensino e trabalhados pela articulação objetivos-conteúdos-métodos e formas de organização do ensino, dentro do contexto educacional e social (LIBÂNEO, 2013).

Na seleção dos conteúdos é necessário levar em consideração o programa escolar e o programa pessoal do professor. Segundo Pilleti (1985), os critérios para seleção de conteúdos são: validade, significação, utilidade, possibilidade de elaboração pessoal, viabilidade e flexibilidade. De acordo com Gil (2018), os critérios para selecionar conteúdos são: vinculação aos objetivos; autossuficiência; validade; significância; utilidade; flexibilidade; adequação à diversidade dos estudantes e adequação ao tempo

Libâneo (2013) apresenta, também, alguns princípios que devem ser considerados para a seleção de conteúdo: correspondência entre objetivos gerais e conteúdo; caráter cientifico; caráter sistemático, relevância social e acessibilidade e solidez.

Em relação à organização dos conteúdos, ele deve ser dividido em três níveis: aula (um dia), tópico (assuntos dentro de uma aula) e unidade (partes dos tópicos), considerando os critérios de continuidade, sequência e integração (MALHEIROS, 2019).

Logo, a seleção e organização dos conteúdos tornam-se tarefas importantes para o professor, pois são a base informativa e formativa do processo transmissãoassimilação (LIBÂNEO, 2013). Devem, então, ser realizadas de forma coerente e criteriosa com as necessidades sociais e individuais dos estudantes, a fim de que o processo de aprendizagem ocorra de maneira significativa, evitando, assim, a sobrecarga de assuntos, que muitas vezes, não levam em consideração os conteúdos realmente indispensáveis de serem assimilados, a própria capacidade de assimilação dos alunos e a consolidação da aprendizagem (LIBÂNEO, 2013). 


\section{MÉTODOS DE ENSINO}

Ao refletir sobre os principais métodos e técnicas de ensino é importante compreender, primeiramente, o significado desses termos. Método é caminho planejado para se chegar ao objetivo e a técnica é a operacionalização do método (MALHEIROS, 2019). De acordo com Libâneo (2013), os métodos de ensino são determinados pela relação entre objetivo e conteúdo, referindo-se aos meios para alcançar os objetivos gerais e específicos.

Os métodos de ensino podem ser classificados em: exposição, trabalho independente, trabalho em grupo e outros métodos de ensino (MALHEIROS, 2019). Seguem abaixo alguns exemplos citados por Malheiros (2019) e Libâneo (2013):

- Métodos de exposição: exposição oral, demonstração, ilustração etc.

- Métodos de trabalho independente: estudo dirigido individual, grupos de interesse, estudo de caso

- Métodos de trabalho em grupo: jogos, dramatização, debate etc.

- Outros métodos de ensino: Montessori, projetos, construtivismo.

Observa-se, portanto, que todos os elementos da didática estão interligados. Logo, definir os métodos de ensino adequados só é possível na medida em que se tem a compreensão dos objetivos a serem alcançados e dos conteúdos que devem ser trabalhados.

\section{AVALIAÇÃO DA APRENDIZAGEM ESCOLAR}

Luckesi (2011) define avaliação como um julgamento qualitativo sobre o processo de ensino-aprendizagem. Esse julgamento existe para auxiliar o professor na tomada de decisões e, por isso, não pode ser considerado como aplicação de testes e provas, medição de informações que o aluno foi capaz de memorizar e atribuição de notas aos alunos. 
Para Haydt (2006) existe uma clara distinção entre testar, medir e avaliar. Segunda a autora, testar significa verificar um desempenho através de situações previamente organizadas, chamadas de testes, enquanto medir está relacionado a descrição de um fenômeno do ponto de vista quantitativo. Por fim, avaliar é interpretar dados quantitativos e qualitativos pra obter um parecer ou julgamento de valor, tendo por base padrões ou critérios.

A avaliação, segundo Libâneo (2013) deve ser construída em etapas: verificação (coleta de dados), qualificação (relação entre os dados) e apreciação (reflexão sobre os resultados). Assim, ela poderá refletir o avanço real e potencial do aluno.

Outro aspecto importante da avaliação da aprendizagem é que ela tem um propósito específico em cada fase que é realizada. No início do processo é chamada de avaliação diagnóstica, pois tem o objetivo de analisar o ponto de partida, ou seja, aquilo que o aluno já conhece. Durante o processo acontece a avaliação formativa, objetivando corrigir os caminhos tomados. Por fim, é realizada a avaliação somativa, a qual analisa o conjunto para saber se o objetivo educacional foi alcançado, com característica de controle e classificação (LUCKESI, 2011).

Como foi visto anteriormente, Bejamin Bloom, criador da Taxonomia de Bloom, também contribuiu com sua teoria para a área da avaliação do ensino (GIL, 2018). Tal estudo divide os domínios do conhecimento em: cognitivo (avalia aquilo que o aluno sabe), afetivo (avalia aspectos de relações interpessoais) e psicomotor (avalia habilidades para a execução de tarefas).

Isto posto, o processo de avaliação da aprendizagem escolar deve ser bem planejado e organizado, pois proporciona inúmeros benefícios, tais como: fornece as bases para o planejamento; ajusta políticas e práticas curriculares, estabelece situações de aprendizagens; melhora 0 aprendizado e 0 ensino, entre outros aspectos (SANT'ANNA, 2014). 


\section{CONSIDERAÇÕES FINAIS}

Ao longo dos estudos sobre a Didática e de seus principais elementos, nota-se a sua contribuição para o trabalho dos profissionais da educação. Ela oferece um aporte teórico e prático indispensável à formação dos professores, pois esclarece os fatores condicionantes do processo de instrução e ensino e, ao mesmo tempo, oferece subsídios para o exercício da tarefa docente (LIBÂNEO, 2013).

O presente artigo buscou contribuir para que os docentes reformulem suas práticas a partir da reflexão sobre a história da didática e seus elementos que fomentam o aperfeiçoamento do desempenho dos professores, quais sejam: objetivos educacionais, planejamento educacional, a seleção e organização de conteúdo, os métodos de ensino e a avaliação da aprendizagem escolar.

A compreensão e a consciência da utilização dos aspectos da didática na prática docente, aliadas a realidade da instituição e dos alunos, farão com que a aprendizagem se torne realmente significativa para todos os envolvidos no processo de ensino aprendizagem.

\section{REFERÊNCIAS}

GIL, Antonio Carlos. Didática no Ensino Superior. São Paulo: Atlas, 2018.

HAYDT, R.C.C. Curso de Didática Geral. 8 ed. São Paulo: Ática, 2006.

LIBÂNEO, José Carlos. Didática. São Paulo: Cortez, 2013.

LUCKESI, Cipriano Carlos. Avaliação da Aprendizagem Escolar: Estudos e Proposições. 22 ed. São Paulo: Cortez, 2011.

MALHEIROS, Bruno Taranto. Didática Geral. Rio Janeiro: LTC, 2019.

PILLETI, N. Didática Geral. São Paulo: Pioneira, 1985. 
SANT'ANNA, Ilza Martins. Por que avaliar? Como avaliar? Critérios e Instrumentos. 17 ed. Petrópolis, RJ: Vozes, 2014.

Enviado: Maio, 2021.

Aprovado: Agosto, 2021. 